\title{
Enhanced pore space analysis by use of $\mu$-CT, MIP, NMR, and SIP
}

\author{
Zeyu Zhang ${ }^{1}$, Sabine Kruschwitz ${ }^{2,3}$, Andreas Weller ${ }^{4}$, and Matthias Halisch \\ ${ }^{1}$ Southwest Petroleum University, School of Geoscience and Technology, 610500 Chengdu, China \\ ${ }^{2}$ Federal Institute for Material Research and Testing (BAM), 12205 Berlin, Germany \\ ${ }^{3}$ Technische Universität Berlin, Institute of Civil Engineering, 13355 Berlin, Germany \\ ${ }^{4}$ Clausthal University of Technology, Institute of Geophysics, 38678 Clausthal-Zellerfeld, Germany \\ ${ }^{5}$ Leibniz Institute for Applied Geophysics (LIAG), 30655 Hannover, Germany
}

Correspondence: Zeyu Zhang (zeyuzhangchina@ 163.com)

Received: 6 May 2018 - Discussion started: 14 May 2018

Revised: 13 October 2018 - Accepted: 15 October 2018 - Published: 7 November 2018

\begin{abstract}
We investigate the pore space of rock samples with respect to different petrophysical parameters using various methods, which provide data on pore size distributions, including micro computed tomography $(\mu-\mathrm{CT})$, mercury intrusion porosimetry (MIP), nuclear magnetic resonance (NMR), and spectral-induced polarization (SIP). The resulting cumulative distributions of pore volume as a function of pore size are compared. Considering that the methods differ with regard to their limits of resolution, a multiple-length-scale characterization of the pore space is proposed, that is based on a combination of the results from all of these methods. The approach is demonstrated using samples of Bentheimer and Röttbacher sandstone. Additionally, we compare the potential of SIP to provide a pore size distribution with other commonly used methods (MIP, NMR). The limits of resolution of SIP depend on the usable frequency range (between 0.002 and $100 \mathrm{~Hz}$ ). The methods with similar resolution show a similar behavior of the cumulative pore volume distribution in the overlapping pore size range. We assume that $\mu$-CT and NMR provide the pore body size while MIP and SIP characterize the pore throat size. Our study shows that a good agreement between the pore radius distributions can only be achieved if the curves are adjusted considering the resolution and pore volume in the relevant range of pore radii. The MIP curve with the widest range in resolution should be used as reference.
\end{abstract}

\section{Introduction}

Transport and storage properties of reservoir rocks are determined by the size and arrangement of the pores. In this paper we use the term geometry to refer to the relevant pore sizes, such as the pore throat radius, pore body radius, body to throat ratio, shape of the pore, and pore volume corresponding to a certain pore radius. Different methods have been developed to determine the pore size distribution of rocks. These methods are based on different physical principles. Therefore, it can be expected that the methods recognize different geometries and sizes. Additionally, the ranges of pore sizes that are resolved by the methods are different (Meyer et al., 1997). Rouquerol et al. (1994) stated in the conclusions of their recommendations for the characterization of porous solids that no experimental method provides the absolute value of parameters such as porosity, pore size, surface area, or surface roughness. It should be noted that these parameters indicate a fractal nature. That means that the value of the parameter depends on the spatial resolution of the method.

An enhanced pore space analysis using different methods should be able to provide a better description of the pore space over a wide range of pore sizes. Our study of pore space analysis is based on the following methods: micro computed tomography ( $\mu$-CT), mercury intrusion porosimetry (MIP), nuclear magnetic resonance (NMR), and spectralinduced polarization (SIP). The first three methods can be regarded as standard methods to derive a pore size distribution. Since these methods can reveal the inner structure of the rocks, they are widely applied in geosciences (e.g., Halisch 
et al., 2016b; Mees et al., 2003; Behroozmand et al., 2015; Weller et al., 2015). The main aim of our paper is to integrate an electrical method in this study. Electrical conductivity and polarizability (or real and imaginary parts of electrical conductivity) are fundamental physical properties of porous materials. The SIP method measures the low-frequency electric behavior of rocks and soil material that can be efficiently represented by a complex electric conductivity (e.g., Slater and Lesmes, 2002). The electric properties of a porous material depend, to a large extent, on key parameters including the porosity, the grain and pore size distribution, the specific internal surface, the tortuosity, the saturation, and the chemical composition of the pore-filling fluids. SIP is a nondestructive method that can be applied to characterize the geometry of the pore system. Müller-Huber et al. (2018) proposed the integration of SIP in a combined interpretation with NMR and MIP measurements for carbonate rocks in order to use the partly complementary information of each method. The SIP method is used to explore correlations between parameters derived from complex conductivity spectra and specific pore space properties. We go a step further and directly compare the pore size distributions derived from the different methods. Procedures to derive pore size distributions from induced polarization (IP) data have been proposed only recently (Florsch et al., 2014; Revil et al., 2014; Niu and Zhang 2017; Zhang et al., 2017).

We are aware that further methods can be applied for the characterization of pore size distribution, e.g., synchrotronradiation-based computed tomography (Peth et al., 2008), focused ion beam tomography (Keller et al., 2011), transmission electron microscopy (Gaboreau et al., 2012), scanning electron microscopy (SEM), ${ }^{14} \mathrm{C}$ labeled methylmethacrylate method (Kelokaski et al., 2005), and gas adsorption and desorption method (BET; Avnir and Jaroniec, 1989).

Our study presents an approach to describe and quantify the pore space of porous material by combining the results of methods with different resolution. Samples of Bentheimer and Röttbacher sandstone are investigated by $\mu$-CT, MIP, NMR, and SIP. Each method provides the pore size distribution in a limited range of resolution. It is not our intention to combine the data of the different methods in a joint inversion to get a more reliable pore size distribution as proposed by Niu and Zhang (2017). We prefer to compare the resulting pore size distributions to each other to get two different pore radius distributions, one for the pore body radius and one for the pore throat radius. The comparison of the two curves enables the determination of the ratio between pore body and pore throat radius. A joint inversion that ignores the difference between pore body and pore throat provides a simplified model that ignores the complexity of pore space geometry.

Considering the fractal nature of pore space geometry, an attempt is made to determine the fractal dimension of the pore volume distribution for the two investigated samples. The fractal dimension is a useful parameter for up- and downscaling of geometrical quantities. Zhang and Weller (2014) investigated the fractal behavior of the pore volume distribution by capillary pressure curves and NMR $T_{2}$ distributions of sandstones. Considering the differences in fractal dimension resulting from the two methods, they concluded a differentiation into surface dimension and volume dimension. Additionally, the fractal dimension is used in methods of permeability prediction (e.g., Pape et al., 2009).

\section{Theory}

The pore size distribution resulting from different methods has to be compared and evaluated. We prefer a comparison based on the cumulative volume fraction of pores $V_{\mathrm{c}}$, which is expressed by

$$
V_{\mathrm{c}}=\frac{V(<r)}{V_{\mathrm{p}}},
$$

with $V_{\mathrm{p}}$ being the total pore volume, and $V(<r)$ the cumulative volume of pores with radii less than $r$. A graph displaying the logarithm of $V_{\mathrm{c}}$ versus the logarithm of the pore radius offers the advantage that the slope of the curves is related to the fractal dimension of the pore volume (Zhang and Weller, 2014).

Fractal theory is applied to describe the structure of geometric objects (Mandelbrot, 1977, 1983). At molecular size and microscopic range, surfaces of most materials including those of natural rocks show irregularities and defects that appear to be self-similar on variation of resolution (Avnir et al., 1984). A self-similar object is characterized by similar structures at different scales. The regularity of self-similar structures can be quantified by the parameter of fractal dimension $D$. Pape et al. (1982) first proposed a fractal model (the socalled "pigeon-hole model" or "Clausthal concept") for the geometry of rock pores. Fractal dimension describes the size of geometric objects as a function of resolution. This parameter has proved to be useful in the comparison of different methods that determine distributions of pores in sandstones and carbonates (e.g., Zhang and Weller, 2014; Ding et al., 2017).

From MIP, the entry sizes of pores and cavities, which is referred to as pore throat radius $r_{\mathrm{t}}$, can be determined according to the Washburn equation (Washburn, 1921)

$r_{\mathrm{t}}=-\frac{2 \cdot \gamma \cdot \cos \theta}{P_{\mathrm{c}}}$

with $\gamma=0.48 \mathrm{~N} \mathrm{~m}^{-1}$ being the surface tension of mercury, $\theta=140^{\circ}$ the contact angle between mercury and the solid minerals, and $P_{\mathrm{c}}$ the pressure of the liquid mercury that is referred to as capillary pressure.

Starting with low pressure, the pores with larger pore throats are filled with mercury. While increasing the pressure, the pores with smaller throats are filled. Reaching a certain 


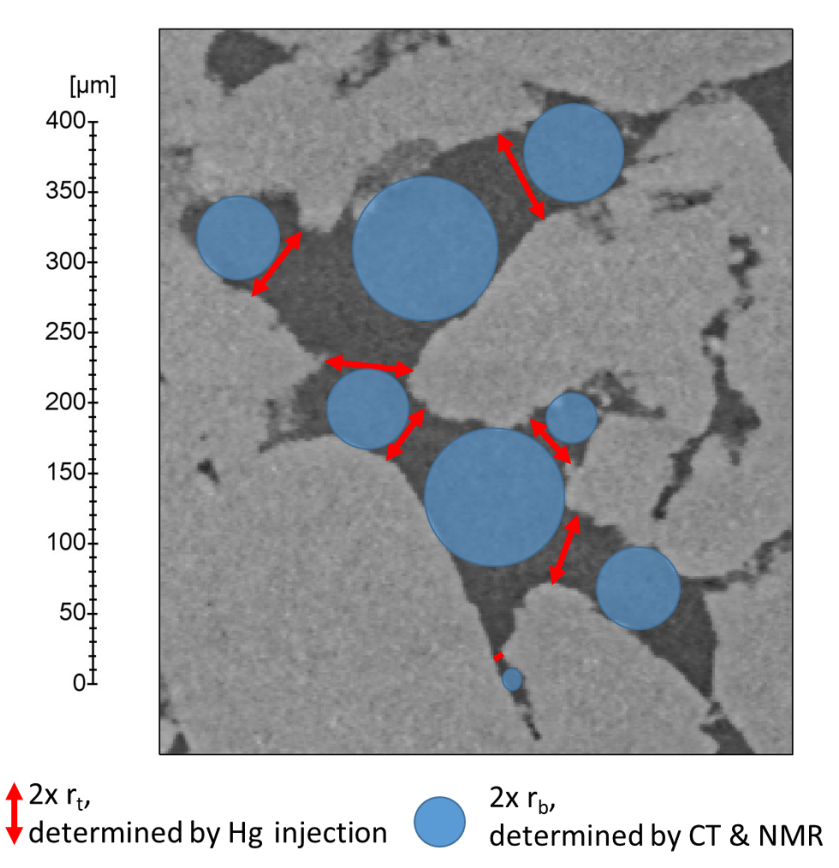

Figure 1. Zoomed-in 2-D slice view of sample BH5-2 in order to visualize pore bodies (blue circles, detected by NMR and digital image analysis (DIA) of $\mu$-CT data) and pore throats (red lines with arrows, detected by MIP).

pressure level $P_{\mathrm{c}}$, a cumulative volume of mercury $\left(V_{\mathrm{Hg}}\right)$ has intruded into the sample that corresponds to the pore volume being accessible by pore throat radii larger or equal $r_{\mathrm{t}}$ according to Eq. (2). Figure 1 shows a 2-D image of the pore space of sample BH5-2 (information is given in Sect. 3) indicating the pore throat radius $r_{\mathrm{t}}$ as measured by MIP by red arrows. Fluid flow properties, and hence the injection pressure of mercury, solely depend on the narrowest pore diameter in the flow path that corresponds to the pore throat diameter. The cumulative volume of mercury $V_{\mathrm{Hg}}$ corresponds to the pore volume $V\left(>r_{\mathrm{t}}\right)$. It should be noted that the volume of larger pores, which are shielded by narrower throats, is attributed to the pore throat radius (e.g., Kruschwitz et al., 2016). Knowing the total pore volume $V_{\mathrm{p}}$, the saturation of the sample with mercury $S_{\mathrm{Hg}}$ can be determined. A conventional capillary pressure curve displays the relationship between the saturation of the sample with mercury $S_{\mathrm{Hg}}$ as a function of capillary pressure $P_{\mathrm{c}}$ (e.g., Thomeer, 1960). Using the following simple transformations,

$S_{\mathrm{Hg}}=\frac{V_{\mathrm{Hg}}}{V_{\mathrm{p}}}=\frac{V\left(>r_{\mathrm{t}}\right)}{V_{\mathrm{p}}}=\frac{V_{\mathrm{p}}-V\left(<r_{\mathrm{t}}\right)}{V_{\mathrm{p}}}=1-V_{\mathrm{c}}$,

the cumulative volume fraction of pores $V_{\mathrm{c}}$ as defined in Eq. (1) can be determined as a function of $r_{\mathrm{t}}$.

The NMR relaxometry experiment records the decay of transversal magnetization. The measured transversal decay curve is decomposed in a distribution of relaxation times $b\left(T_{2}\right)$. The individual relaxation time $T_{2}$ is attributed to a pore space with a certain surface-to-volume ratio $A / V$ by

$$
\frac{1}{T_{2}}=\rho\left(\frac{A}{V}\right)
$$

with $\rho$ being the surface relaxivity. Considering that for a capillary tube model with cylindrical pores of radius $r$, the surface-to-volume ratio equals $2 / r$, we get the following linear relationship between pore radius $r$ and relaxation time $T_{2}$ (e.g., Kleinberg, 1996):

$r=2 \rho T_{2}$.

It should be noted that the NMR method resolves the radius $r_{\mathrm{b}}$ that corresponds to the maximal distance to the pore wall. It can be represented by the pore radius of the largest sphere that can be placed inside this pore as shown in Fig. 1 .

Another approach to derive a pore size distribution is based on the SIP method. Relations between grain or pore size and IP parameters have been reported in a variety of studies (e.g., Slater and Lesmes, 2002; Scott and Barker, 2003; Binley et al., 2005; Leroy et al., 2008; Revil and Florsch, 2010). Polarization effects of natural materials are caused by different charging and discharging processes of some polarizing elements such as grain surface, pore throat, membrane, and electrical double layer. Following an approach proposed by Schwarz (1992), the complex conductivity of an individual polarization element can be presented by a Debye model. It is assumed that the recorded spectra result from a superposition of polarization processes characterized by different relaxation times. This approach has been adopted to generate synthetic spectra of electrical conductivity from distributions of grain sizes (e.g., Revil and Florsch, 2010) or pore sizes (e.g., Niu and Zhang, 2017).

A decomposition of the spectra is needed to derive the relaxation time distribution. Florsch et al. (2014) demonstrated that a variety of models can be used as kernel for the decomposition of the spectra. Revil et al. (2014) compare the results of Debye and Warburg decomposition. Their argumentation, which is based on mechanistic grain size models describing the polarization of charged colloidal particles and granular material, supports the application of the Warburg decomposition that results in a narrower distribution of polarization length scales. It should be noted that a uniform grain size does not automatically generate a uniform pore size. Besides, it can be clearly seen by the scanning electron microscopy images that the investigated sandstones feature a distinct range of both grain and pore (throat) sizes. Considering that the pore size and not the grain size controls the polarization of sandstones, as observed by different authors (e.g., Scott and Barker, 2003; Niu and Revil, 2016), a wider distribution of length scales can be expected. According to our opinion, there are no clear indications for superiority of the Warburg decomposition. Up to now, a theoretical model that confirms the validity of the Warburg model in describing the polarization of a simple pore space geometry has not been 
presented. Therefore, we prefer to use the Debye decomposition, which has proved to be a useful tool in the processing of IP data in both the time and frequency domain (e.g., Terasov and Titov, 2007; Weigand and Kemna, 2016). The algorithm described by Nordsiek and Weller (2008) provides the electrical relaxation time distribution as well as the total chargeability from complex conductivity spectra.

According to the assumption that the electrical relaxation time and pore size are related to each other, the specific chargeability at a certain relaxation time corresponds to the pore volume attributed to a certain pore size, and the total chargeability is attributed to the total pore volume of the sample. The volume fraction $V_{\mathrm{c}}$ corresponds to the ratio of cumulative chargeability to total chargeability. To transform the relaxation time distribution into a pore size distribution, we adopt the approach proposed by Schwarz (1962) and applied by Revil et al. (2012) for the Stern layer polarization model:

$r=\sqrt{2 \tau D_{(+)}}$,

with $D_{(+)}$being the diffusion coefficient of the counter-ions in the Stern layer and $\tau$ being the relaxation time. Originally, this equation describes the relation between the radius of spherical particles in an electrolyte solution and the resulting relaxation time. Although it remains arguable whether or not the radius of spherical grains can be simply replaced by the pore radius (Weller et al., 2016), we generally follow this approach. Additionally, we assume a constant diffusion coefficient $D_{(+)}=3.8 \times 10^{-12} \mathrm{~m}^{2} \mathrm{~s}^{-1}$ as proposed by Revil (2013).

The signal amplitude at a given relaxation time corresponds to the pore volume related to the pore radius determined by Eq. (6). Considering the experience that the polarization is related to the specific surface area per unit pore volume (e.g., Weller et al., 2010), we assume that the IP signals are caused by the ion-selected active zones in the narrow pores that are comparable with the pore throats. Their size is quantified by the pore throat radius $r_{\mathrm{t}}$. Following the procedure proposed by Zhang et al. (2017), the cumulative volume fraction $V_{\mathrm{c}}$ corresponds to the ratio of cumulative chargeability to total chargeability. Considering the restricted range of pore radii $(0.1-25 \mu \mathrm{m})$ resolved by SIP, a correction of the maximum $V_{\mathrm{c}}$ becomes necessary.

\section{Samples and methods}

For this study, two different sandstone samples have been used. Firstly, a Bentheimer sandstone, sample BH5-2. The shallow-marine Bentheimer sandstone was deposited during the Early Cretaceous (roughly 140 million years ago) and forms an important reservoir rock for petroleum (Dubelaar et al., 2015). This sandstone is widely used for systematic core analysis due its simple mineralogy and the quite homogeneous and well-connected pore space. It is composed out of $92 \%$ quartz, contains some feldspar, and about $2.5 \%$ vol of kaolinite (Peksa et al., 2015), which is a direct alteration product of the potassium-bearing feldspar minerals. Accordingly, surface area and surface relaxivity values are mostly controlled by the kaolinite for this rock.

Secondly, a Röttbacher sandstone, sample RÖ10B, has been used. The Röttbacher sandstone is a fine-grained, more muscovite-illite containing, and rather homogeneous material that was deposited during the Lower Triassic era (roughly 250 million years ago). It is suitable for solid stonework and has been widely used as building material for facades as well as for indoor and outdoor flooring. The Röttbacher sandstone was included in a study on the relationship of pore throat sizes and SIP relaxation times reported by Kruschwitz et al. (2016). This sandstone consists mostly of quartz, but features a higher amount of clay minerals than the Bentheimer sample. Additionally, iron-bearing minerals (e.g., haematite) have been formed during its arid depositional environment, giving this sandstone a distinct reddish color. Accordingly, surface area and surface relaxivity are dominated by the clay and iron-bearing minerals and should be significantly different than for the BH5-2 sample.

The experimental methods used in this study include digital image analysis (DIA) based on micro computed tomography $(\mu-\mathrm{CT})$, mercury intrusion porosimetry (MIP), nuclear magnetic resonance (NMR), and spectral-induced polarization (SIP).

For this study, a nanotom S $180 \mathrm{X}$-ray $\mu$-CT instrument (GE Sensing \& Inspection Technologies $\mathrm{GmbH}$ ) has been used. The sample size for $\mu$-CT scanning is $2 \mathrm{~mm}$ diameter and $4 \mathrm{~mm}$ length. For pore network separation, a combination of manual thresholding and watershed algorithms has been applied to achieve the qualitatively best separated pore space. Additionally, separation results have been cross checked with the images of scanning electron microscopy (SEM). More details on the DIA workflow can be found in Halisch et al. (2016a). The DIA of the 3-D $\mu$-CT data sets provide, for each individual pore, the volume and the pore radius of the largest sphere that can be placed inside this pore (maximum inscribed sphere method; e.g., Silin and Patzek, 2006) as indicated by the blue circles in Fig. 1. Note that Fig. 1 displays a 2-D slice with circles. The DIA is performed in 3-D volumes and provides spheres. The resulting equivalent pore radius is referred to as pore body radius $r_{\mathrm{b}}$. Although the true extent of the pore is not caught properly, the derived $r_{\mathrm{b}}$ from DIA is a good estimate of the average radius. Adding up the pore volumes starting with the lowest pore radius yields the cumulative volume fraction of pores $V_{\mathrm{c}}$ (Eq. 1) as a function of the pore body radius $r_{\mathrm{b}}$. The $\mu$ CT method can only resolve the part of the pore space with pore sizes larger than the spatial resolution of the 3-D image. Considering a voxel size of $1.75 \mu \mathrm{m}$ of the $3-\mathrm{D}$ data set, and a minimum extension of pores of 2 voxels in one direction, which can be separated by the algorithm, a minimum pore size of $3.5 \mu \mathrm{m}$ (or minimum pore radius of $1.75 \mu \mathrm{m}$ ) has 
to be regarded; as for this study, the CT resolution limit is $1.75 \mu \mathrm{m}$. Therefore, the pore volume determined by $\mu$-CT does not take into account the pore space with radii smaller than $1.75 \mu \mathrm{m}$.

The MIP experiments have been conducted with the PASCAL 140/440 instrument from Thermo Fisher (Mancuso et al., 2012), which covers a pressure range between 0.015 and $400 \mathrm{MPa}$ corresponding to a pore throat radius range from (at best) $1.8 \mathrm{~nm}$ to $55 \mu \mathrm{m}$. The samples have been evacuated before the MIP experiment.

The NMR experiments have been performed with a Magritek rock core analyzer instrument operating at a Larmor frequency of $2 \mathrm{MHz}$ at room temperature $\left(\sim 20^{\circ} \mathrm{C}\right)$ and ambient pressure. After drying at $105^{\circ} \mathrm{C}$ for more than $24 \mathrm{~h}$ in vacuum, the samples have been fully saturated with tap water with a conductivity of about $25 \mathrm{mS} \mathrm{m}^{-1}$. NMR measurements can be calibrated to get the porosity of the sample. The early time decay signal corresponds to the total water content. The range of resolved pore body radii depends on the used value of surface relaxivity. The amplitude $b$ attributed to an individual relaxation time $T_{2}$ is related to the volume fraction of pores with the respective pore radius. Considering the larger pores, the resulting radius corresponds to $r_{\mathrm{b}}$. The smaller pore throats with lower volume yield a lower signal at shorter relaxation times. The cumulative volume fraction of pores $V_{\mathrm{c}}$ is determined by adding up the individual $b$ values starting from the smallest relaxation time and normalizing to the total sum of all $b$ values.

Complex conductivity spectra were recorded using a four-electrode sample holder as described by Schleifer et al. (2002). The spectra were acquired with the impedance spectrometer ZEL-SIP04 (Zimmerman et al., 2008) in a frequency range between $0.002 \mathrm{~Hz}$ and $45 \mathrm{kHz}$ at a constant temperature of about $20^{\circ} \mathrm{C}$. Considering that the complex conductivity spectra are affected by electromagnetic coupling effects, Maxwell-Wagner relaxation and dielectric effects at higher frequencies and by a lower signal-to-noise ratio for lower frequencies, we focus on the frequency range between 0.01 and $100 \mathrm{~Hz}$. The samples were fully saturated with a sodium-chloride solution with a conductivity of $100 \mathrm{mS} \mathrm{m}^{-1}$. At least two measurements were performed for each sample to verify the repeatability. Considering the limited frequency interval, the SIP method solely resolves a range of pore radii that depends on the diffusion coefficient. Hence, using $D_{(+)}=3.8 \times 10^{-12} \mathrm{~m}^{2} \mathrm{~s}^{-1}$ in Eq. (6), we get a range of pore radii between 0.1 and $10 \mu \mathrm{m}$. Smaller pore sizes are hidden by Maxwell -Wagner relaxation and dielectric effects that are not easily related to pore geometry.

Permeability measurements have been performed by using a steady-state gas permeameter (manufactured by Westphal Mechanik, Celle, Germany), using nitrogen as the flowing fluid. This device features a so-called "Fancher-type" core holder as described by Rieckmann (1970). With this special type of core holder, significantly lower confining pressures are needed than by using a conventional "Hassler-type" core holder (12 bar for the "Fancher-type" core holder versus min. 35-50 bar for the "Hassler-type" core holder), leading to much less initial mechanical influence (compaction) on the sample material. Measurements have been derived under steady-state flow conditions with accordingly low flow rates in the range from 3 to $5 \mathrm{~mL} \mathrm{~min}^{-1}$, leading to measured pressure differentials in the range from 2 to 7 mbar from sample inlet to outlet. The derived apparent permeability values have been corrected to address the Klinkenberg effect of gas slippage (Klinkenberg, 1941; API, 1998). Due to the usage of a steady-state technique with low gas-flow rates, we consider that correction of the Forchheimer effect of inertial resistance can be neglected (API, 1998).

\section{Results}

\subsection{Petrophysical properties}

Figure 2 (panels a and c) gives 2-D impressions of the pore system of the Bentheimer sandstone sample. The pore space in general is very well connected, featuring many large and open pores (Fig. 2a and c, blue arrows) and can be described as a classical pore body-pore throat-pore body system. Small pores are mostly found within the clayey agglomerations, which act as (macro) pore-filling material (Fig. 2a and c, red arrows) and which are homogeneously distributed throughout the sample material. Figure $2 \mathrm{e}$ gives an impression of the 3-D pore distribution of this sandstone, derived by $\mu$-CT image processing. This favorable structure is directly reflected by the petrophysical properties of this sandstone. The sample investigated in our study is characterized by a porosity of 0.238 measured by MIP, a gas permeability of $4.25 \times 10^{-13} \mathrm{~m}^{2}$, and a specific surface area of $0.3 \mathrm{~m}^{2} \mathrm{~g}^{-1}$ determined by the nitrogen adsorption method.

Figure 2 (panels $b$ and $d$ ) shows the pore space of the Röttbacher sandstone sample from 2-D imaging techniques. Although the (large) pore space is similarly structured as it is for the Bentheimer (pore body-throat-body system; Fig. 2b and $\mathrm{d}$, blue arrows), it is generally reduced (cemented) by clay minerals and features a significantly higher amount of small pores within (Fig. $2 \mathrm{~b}$ and d, red arrows). Accordingly, pore-space-related petrophysical properties classify a more compact rock, which is supported by the 3-D pore distribution, derived by $\mu$-CT image processing (Fig. 2f). The sample used for this study features a porosity of 0.166 measured by MIP, which is lower than for the Bentheimer sandstone. The gas permeability is $3.45 \times 10^{-14} \mathrm{~m}^{2}$, which is less than $10 \%$ of the value determined for the Bentheimer sandstone. The specific surface area has been measured as $1.98 \mathrm{~m}^{2} \mathrm{~g}^{-1}$ and is hence nearly 7 times larger than for sample BH5-2, clearly underlining the impact of the clay content. The petrophysical parameters for both samples are compiled in Table 1 , whereas results from X-ray fluorescence analysis are summarized in Table 2, regarding the most important chem- 

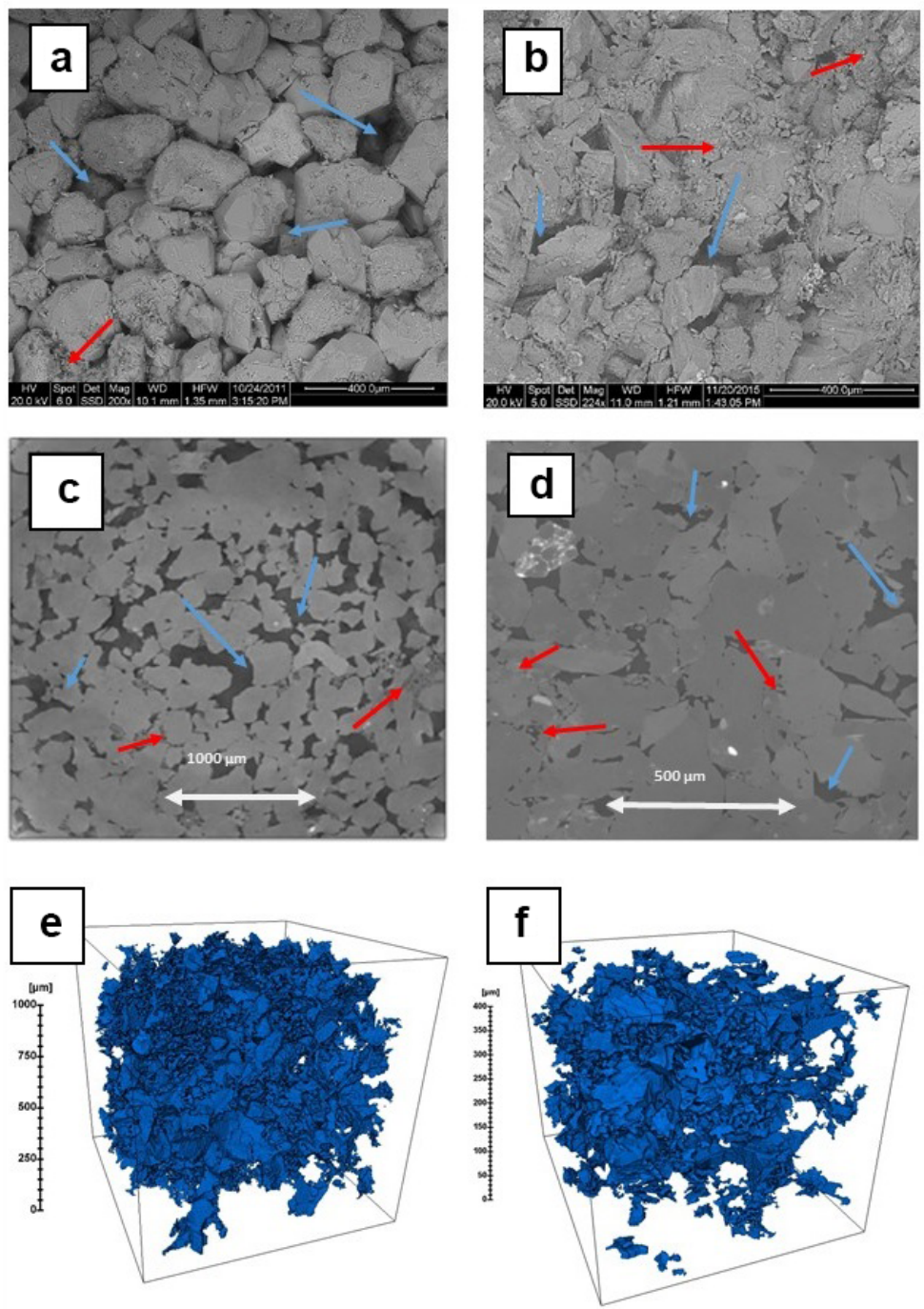

Figure 2. SEM (a) and 2-D (c) and 3-D (e) CT views on the minerals and pore structure of the investigated sample of Bentheimer sandstone, and SEM (b) and 2-D (d) and 3-D (f) CT views on the minerals and pore structure of the investigated sample of Röttbacher sandstone. Blue arrows indicate open-pore spaces, red arrows indicate clay agglomerations and pore fillings.

ical components of both sandstones that have been used for this study.

\subsection{Pore volume fraction}

We applied the $\mu$-CT, MIP, NMR, and SIP methods to get insight into the pore radius distribution of the Bentheimer sandstone sample BH5-2. Figure 3 displays the resolved porosity $\phi_{\mathrm{r}}$ as a function of pore radius for $\mu$-CT and MIP data. The cumulative pore volume while progressing from larger to smaller pores $V(>r)$ is normalized to the total volume of the sample $V_{\mathrm{s}}$ and results in the resolved porosity

$\phi_{r}=\frac{V(>r)}{V}$, which reaches the true porosity $\phi$ as threshold value for $r$ approaching zero.

As shown in Fig. 3, the $\mu$-CT method identifies the largest pores with pore body radii of about $100 \mu \mathrm{m}$. The resolved porosity $\phi_{\mathrm{r}}$ reaches a value of 0.184 at the limit of resolution of the $\mu$-CT method $\left(r_{\mathrm{b}}=1.75 \mu \mathrm{m}\right)$. The nearly horizontal curve progression for $r<17 \mu \mathrm{m}$ indicates that effectively no significant volume of pores with radii lower than $17 \mu \mathrm{m}$ was detected or quantified by $\mu$-CT or DIA, respectively. Accordingly, only $\mu$-CT data for $r>17 \mu \mathrm{m}$ will be taken into account for further analysis.

The MIP identifies the largest pore throats with a radius of about $30 \mu \mathrm{m}$. Reaching the limit of resolution of the MIP, the resolved porosity asymptotically approaches the threshold value of 0.238 . Although both methods, $\mu$-CT and MIP, yield 
Table 1. Petrophysical properties of the samples: porosity $\phi$, permeability $K$, specific surface area $S_{m}$, formation factor $F$, dominant pore radius $r_{\text {dom }}$, effective pore radius $r_{\text {eff }}$, the ratio $r_{\mathrm{b}} / r_{\mathrm{t}}$, fractal dimensions determined from mercury intrusion porosimetry $D_{\mathrm{MIP}}$, nuclear magnetic resonance $D_{\mathrm{NMR}}$, spectral-induced polarization $D_{\mathrm{SIP}}$, the surface relaxivity $\rho$, and the diffusion coefficient $D_{(+)}$.

\begin{tabular}{llrr}
\hline & Unit & BH5-2 & RÖ10B \\
\hline Porosity (triple weighing) & & 0.238 & 0.159 \\
Porosity $(\mu$-CT) & & 0.184 & 0.106 \\
Porosity (MIP) & 0.238 & 0.166 \\
Permeability $K$ & $\mathrm{~m}^{2}$ & $4.25 \times 10^{-13}$ & $3.45 \times 10^{-14}$ \\
Specific surface area & $\mathrm{m}^{2} \mathrm{~g}^{-1}$ & 0.30 & 1.98 \\
Formation factor $F$ & & 14.3 & 11.3 \\
$r_{\text {dom }}(\mathrm{MIP})$ & $\mu \mathrm{m}$ & 11.4 & 4.9 \\
$r_{\text {eff }}=(8 F K)^{0.5}$ & $\mu \mathrm{m}$ & 6.97 & 1.77 \\
$r_{\mathrm{b}} / r_{\mathrm{t}}$ & & 2.57 & 9.13 \\
$D_{\text {MIP }}$ & & 2.678 & 2.640 \\
$D_{\text {NMR }}$ & & 2.776 & 2.661 \\
$D_{\text {SIP }}$ & 2.618 & 2.533 \\
Surface relaxivity $\rho$ & $\mu \mathrm{m} \mathrm{s}^{-1}$ & 54 & 237 \\
Diffusion coefficient $D_{(+)}$ & $\mathrm{m}^{2} \mathrm{~s}^{-1}$ & $3.8 \times 10^{-12}$ & $3.8 \times 10^{-12}$ \\
\hline
\end{tabular}

Table 2. Chemical components of the samples from X-ray fluorescence analysis.

\begin{tabular}{lrrrrrrr}
\hline & \multicolumn{6}{c}{ Selected chemical components from X-ray fluorescence (wt \%) } \\
\cline { 2 - 8 } Sample & $\mathrm{SiO}_{2}$ & $\mathrm{TiO}_{2}$ & $\mathrm{Al}_{2} \mathrm{O}_{3}$ & $\mathrm{Fe}_{2} \mathrm{O}_{3}$ & $\mathrm{CaO}$ & $\mathrm{Na}_{2} \mathrm{O}$ & $\mathrm{K}_{2} \mathrm{O}$ \\
\hline BH5-2 & 97.84 & 0.048 & 1.2 & 0.05 & 0.019 & 0.02 & 0.355 \\
RÖ10B & 87.06 & 0.356 & 6.06 & 1.07 & 0.225 & 0.13 & 3.679 \\
\hline
\end{tabular}

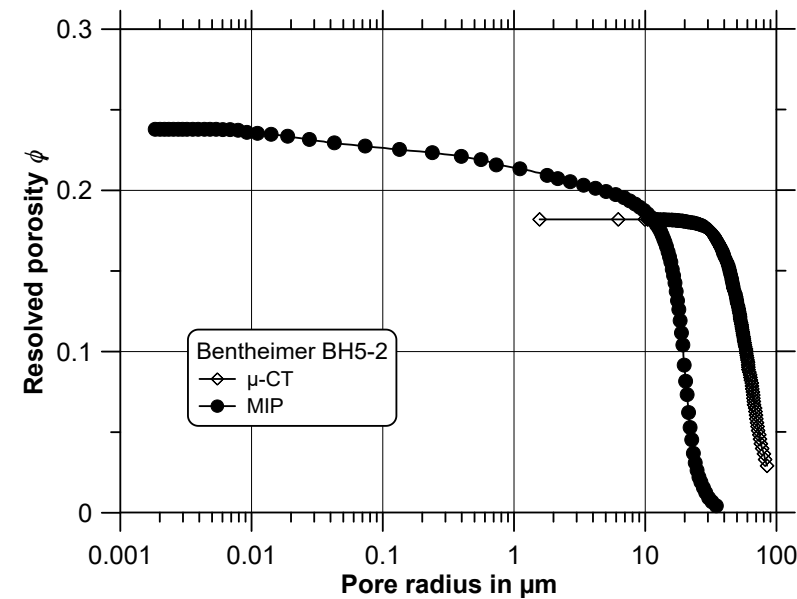

Figure 3. The recognized porosity and pore size range of Bentheimer sandstone sample BH5-2. The maximum porosity recognized by MIP is 0.238 and the maximum porosity recognized by $\mu$-CT is 0.184 .

the pore radius without any adjustable scaling factor, we observe differences between the two curves $\phi_{r}(r)$ in Fig. 3.

The Röttbacher sample was scanned with $1.5 \mu \mathrm{m}$ resolution by $\mu$-CT. As shown in Fig. 4, the $\mu$-CT method identifies

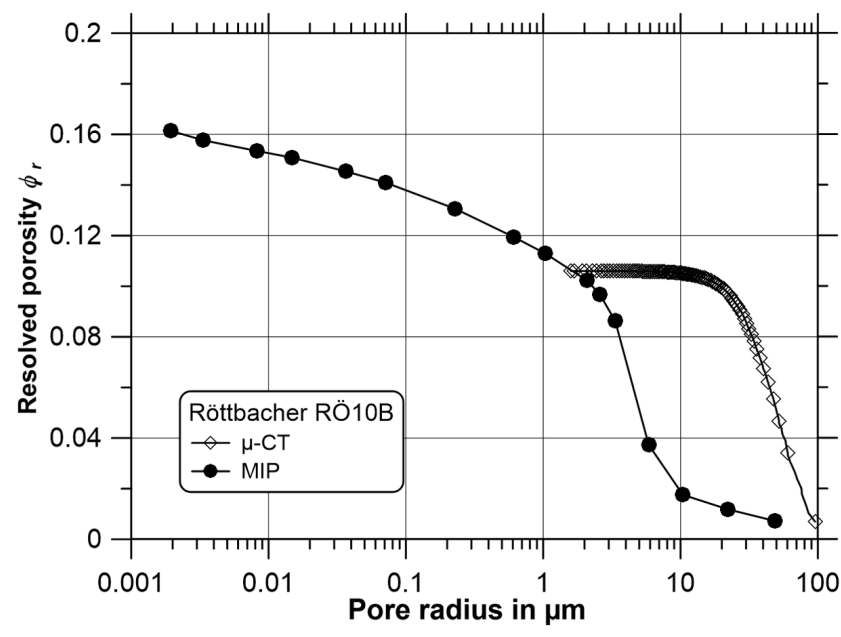

Figure 4. The recognized porosity and pore size range of Röttbacher sandstone sample RÖ10B. The maximum porosity recognized by MIP is 0.166 and the maximum porosity recognized by $\mu$-CT is 0.106 .

the largest pores with pore body radii of about $90 \mu \mathrm{m}$. The resolved porosity $\phi_{r}$ reaches a value of 0.106 at the limit of resolution of the $\mu$-CT method $\left(r_{\mathrm{b}}=1.5 \mu \mathrm{m}\right)$. As observed for the Bentheimer sandstone, the nearly horizontal curve pro- 
Table 3. Geometrical parameters of individual pores derived from $\mu$-CT data of the two samples.

\begin{tabular}{|c|c|c|c|c|c|c|}
\hline \multirow[t]{3}{*}{ Descriptor } & \multicolumn{6}{|c|}{ Sample } \\
\hline & \multicolumn{3}{|c|}{ BH5-2 } & \multicolumn{3}{|c|}{ RÖ10B } \\
\hline & $\min .(\mu \mathrm{m})$ & $\max .(\mu \mathrm{m})$ & mean $(\mu \mathrm{m})$ & $\min .(\mu \mathrm{m})$ & $\max .(\mu \mathrm{m})$ & mean $(\mu \mathrm{m})$ \\
\hline $\begin{array}{l}\text { Equivalent } \\
\text { pore diameter }\end{array}$ & 2.17 & 229.1 & 71.56 & 1.86 & 230.4 & 28.95 \\
\hline $\begin{array}{l}\text { Feret length } \\
\text { (length 3-D) }\end{array}$ & 1.92 & 537.1 & 161.8 & 1.64 & 416.8 & 56.3 \\
\hline $\begin{array}{l}\text { Feret Width } \\
\text { (width 3-D) }\end{array}$ & 1.92 & 307.0 & 87.45 & 1.64 & 265.8 & 28.28 \\
\hline $\begin{array}{l}\text { Feret breadth } \\
\text { (breadth 3-D) }\end{array}$ & 1.75 & 379.4 & 114.7 & 1.5 & 354.8 & 37.99 \\
\hline $\begin{array}{l}\text { Pore volume } \\
\left(\mu \mathrm{m}^{3}\right)\end{array}$ & 5.36 & 6294270 & 315069 & 3.38 & 6404830 & 64809 \\
\hline
\end{tabular}

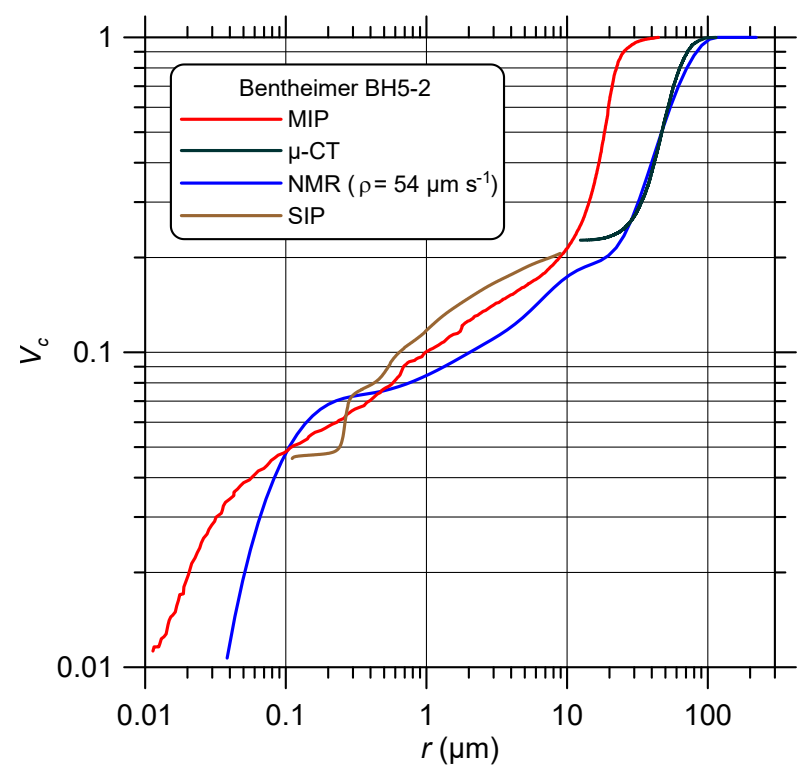

Figure 5. The comparison of $V_{\mathrm{c}}-r$ curves determined from MIP, $\mu$-CT, NMR, and SIP for Bentheimer sandstone sample BH5-2.

gression for $r<10 \mu \mathrm{m}$ indicates that no significant volume of pores with radii lower than $10 \mu \mathrm{m}$ was detected or quantified by $\mu$-CT or DIA, respectively. Accordingly, only $\mu$-CT data for $r>10 \mu \mathrm{m}$ will be taken into account for further analysis.

\subsection{Pore radius distribution}

The description and quantification of the pore space in three dimensions requires morphological parameters such as length, width, and thickness of individual pore segments. The parameters are extracted by image analysis software from

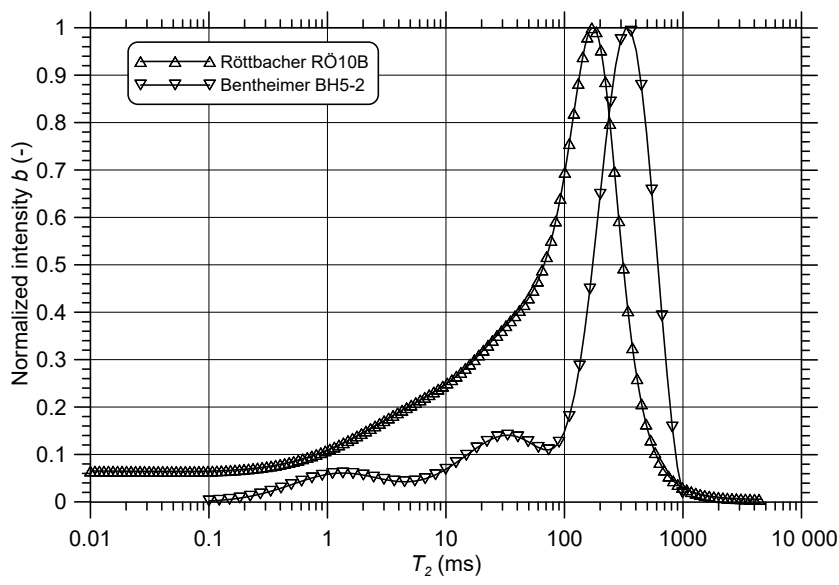

Figure 6. The NMR $T_{2}$ relaxation time distributions of samples BH5-2 and RÖ10B.

3-D $\mu$-CT data. We determined the pore length (maximum length of Feret distribution), pore width (minimum width of Feret distribution), and the equivalent diameter of the analyzed pore segment that corresponds to the spherical diameter with equal voxel volume (Schmitt et al., 2016). The minima, maxima, and mean values of the geometrical parameters derived from $\mu$-CT data of the two samples are compiled in Table 3.

The procedures described above result in an individual curve displaying the logarithm of $V_{\mathrm{c}}$ versus the logarithm of the pore radius for each method.

For Bentheimer sandstone, applying the transformation in Eq. (3) for the MIP data and assuming a true porosity of 0.238 , the cumulative volume fraction of pores $V_{\mathrm{c}}$ can be displayed as a function of pore throat radius as shown in Fig. 5 . The MIP curve gets a fixed position in the plot of Fig. 5 with- 

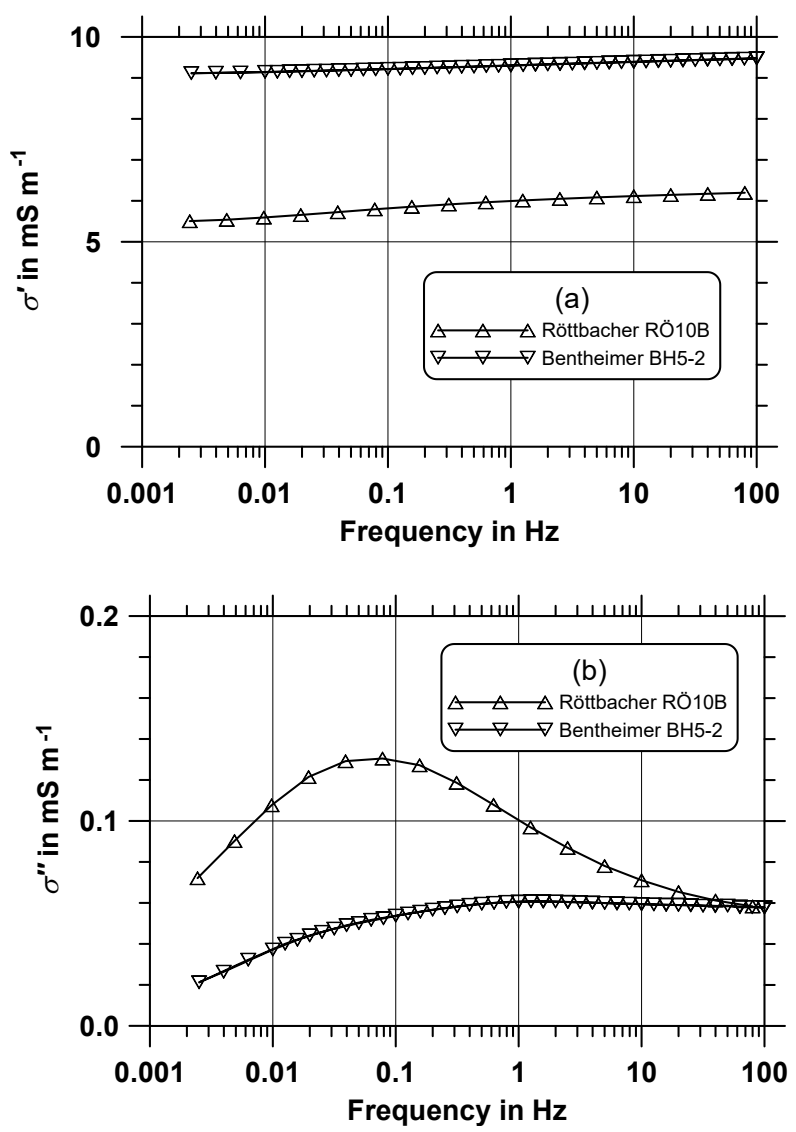

Figure 7. Measured complex conductivity spectra of samples BH52 and RÖ10B; (a) real part of conductivity; (b) imaginary part of conductivity.

out the need for any scaling. It covers a wide range of pore throat radii between 0.0018 and $44.7 \mu \mathrm{m}$.

The curves resulting from other methods have to be adjusted considering the limits of the range of pore radii. The maximum of the $\mu$-CT curve corresponds to $V_{\mathrm{c}}=1$ because no larger pore size has been detected by other methods. The maximum resolved porosity of the sample as detected by MIP reaches 0.238 . The porosity determined by $\mu$-CT reaches only 0.184 (Fig. 3). This value corresponds to a fraction of 0.773 of the porosity determined by MIP. Therefore, the minimum of the $\mu$-CT curve at the pore radius of $17 \mu \mathrm{m}$ has to be adjusted to $V_{\mathrm{c}}=1-0.773=0.227$, because this fraction of pore volume is related to pore body radii smaller than $17 \mu \mathrm{m}$. The shift of the $\mu$-CT curve to larger pore body radii in comparison with MIP is observed in this plot too.

The $T_{2}$ relaxation time distribution of sample BH5-2 is plotted in Fig. 6. It indicates a distinct maximum at a relaxation time of $330 \mathrm{~ms}$ and two weaker maxima at lower relaxation times. The $T_{2}$ relaxation time distribution is transformed into a curve showing the cumulative intensity as a function of $T_{2}$. The total intensity is attributed to the total

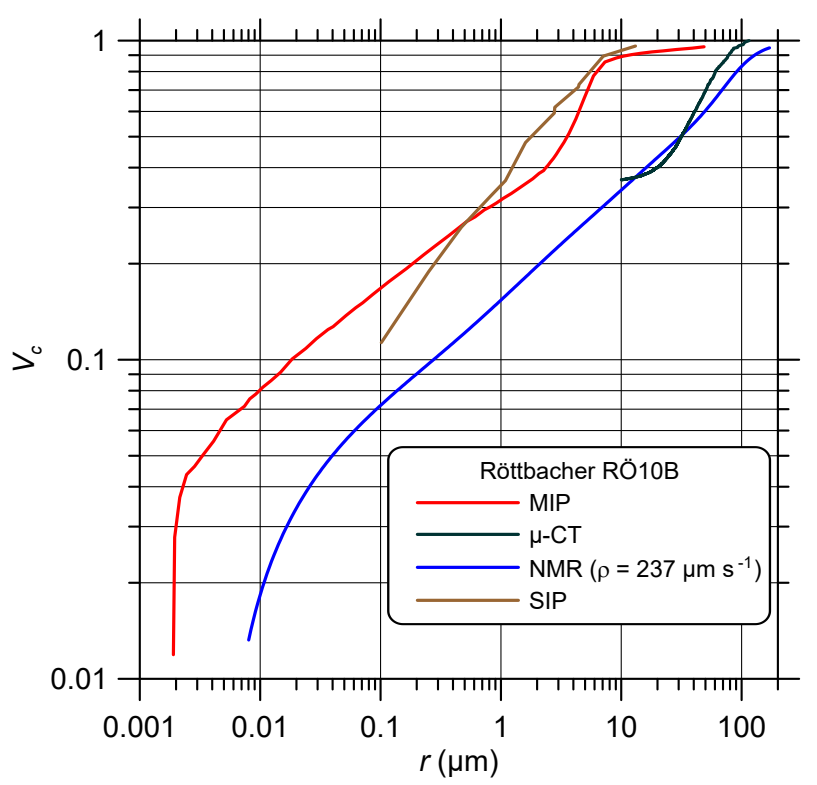

Figure 8. The comparison of $V_{\mathrm{c}}-r$ curves determined from MIP, $\mu$-CT, NMR, and SIP for Röttbacher sandstone sample RÖ10B.

pore volume. The volume fraction $V_{\mathrm{c}}$ corresponds to the ratio of cumulative intensity to total intensity. In order to get the curve $V_{\mathrm{c}}$ as a function of pore radius, the relaxation time $T_{2}$ has to be transformed into a pore radius using the surface relaxivity $\rho$ as scaling factor in Eq. (5). Since both $\mu$ $\mathrm{CT}$ and NMR methods are sensitive to the pore body radius, we expect a similar $V_{\mathrm{c}}-r$ curve in the overlapping range of pore body radii. Assuming a coincidence of the two curves at $V_{\mathrm{c}}=0.5$, the surface relaxivity is adjusted at $\rho=54 \mu \mathrm{m} \mathrm{s}^{-1}$.

The complex conductivity spectra of the Bentheimer sample are displayed in Fig. 7. Considering the frequency range between 0.01 and $100 \mathrm{~Hz}$ and $D_{(+)}=3.8 \times 10^{-12} \mathrm{~m}^{2} \mathrm{~s}^{-1}$, the relaxation time distribution derived from SIP is attributed to a restricted range of pore radii between 0.1 and $10 \mu \mathrm{m}$. Assuming that the polarization signals originate from the pore throats, a similarity of pores size distributions resulting from MIP and SIP can be expected. It should be noted that MIP provides the distribution for a wider range of pore throat radii. Therefore, we adjust the value of $V_{\mathrm{c}}$ at the maximum radius of the SIP to the corresponding value for the MIP curve.

As shown in Fig. 4 for Röttbacher sandstone, the MIP identifies the largest pore throats with a radius of about $50 \mu \mathrm{m}$. Reaching the limit of resolution of MIP, the resolved porosity has a value of 0.166 . Applying the transformation in Eq. (3) on the MIP data and assuming a true porosity of 0.166 , the cumulative volume fraction of pores $V_{\mathrm{c}}$ is displayed as a function of pore radius as shown in Fig. 8.

We suppose that the MIP method detects the whole pore volume, a porosity of 0.106 recognized by $\mu$-CT corresponds to $63.9 \%$ of the total pore volume. Therefore, the minimum 
of the $\mu$-CT curve at the pore radius of $10 \mu \mathrm{m}$ has to be adjusted at $V_{\mathrm{c}}=1-0.639=0.361$, because this fraction of pore volume is related to pore body radii smaller than $10 \mu \mathrm{m}$.

The $T_{2}$ relaxation time distribution of sample RÖ10B is plotted in Fig. 6. It indicates a distinct maximum at a relaxation time of $170 \mathrm{~ms}$. Non-vanishing signals are observed at relaxation times below $0.1 \mathrm{~ms}$. This is an indication of the existence of very small pores in the Röttbacher sandstone.

The position of the NMR curve in the plot of Fig. 8 depends on the surface relaxivity $\rho$. A coincidence with the $\mu$-CT curve at $V_{\mathrm{c}}=0.5$ requires a surface relaxivity of $\rho=$ $237 \mu \mathrm{m} \mathrm{s}^{-1}$ for adjusting the NMR curve.

The complex conductivity spectra of the Röttbacher sample are displayed in Fig. 7. The processing of the spectra according to the described algorithm results in the $V_{\mathrm{c}}-r$ curve as shown in Fig. 8. The SIP curve is fixed at the value $V_{\mathrm{c}}=0.9$ that has been determined by MIP for the maximum pore radius resolved by $\operatorname{SIP}\left(r_{\mathrm{t}}=10 \mu \mathrm{m}\right)$.

\section{Discussion}

Previous studies have compared the $V_{\mathrm{c}}-r$ curves resulting from different methods (e.g., Zhang and Weller, 2014; Zhang et al., 2017; Ding et al., 2017). The slope of the curves was used to get a fractal dimension. It became obvious that the distribution curves indicate remarkable differences that are caused by the physical principles of the used methods. The methods differ with regard to their limits of resolution. The effective resolution of $\mu$-CT is limited by the voxel size. Larger pores can be easily detected. Nevertheless, even though the derived image (voxel) resolution is quite high $(1.75 \mu \mathrm{m})$, both sandstone data sets feature no significant volume of pore body radii smaller than $10 \mu \mathrm{m}$ (BH52) or $17 \mu \mathrm{m}$ (RÖ10B). We assume that this is caused by a complex and sensitive mixture of issues related to image resolution, image quality (phase contrast), reliability of the watershed-algorithm concerning the separation of individual pores, and hence of the complexity of the pore structure of small pores. The MIP yields the widest range of pore throat radii. The pore radius is directly related to the pressure. A similarly wide range of pore body radii can be resolved by NMR. However, the transformation of the NMR transversal relaxation time into a pore radius requires the surface relaxivity as a scaling factor. In a similar way, the transformation of the electrical relaxation time resulting from SIP into a pore radius is based on a scaling factor that depends on the diffusion coefficient. Only a restricted range of pore radii can be resolved by SIP.

Besides the range of pore radii, the geometrical extent of the pore radius differs among the methods. $\mu$-CT enables a geometrical description of the individual pore space considering the shape of the pore. The pore radius can be determined in different ways. We use the average pore radius as an equivalent for the pore body radius $r_{\mathrm{b}}$. MIP is sensitive to the pore throat radius $r_{\mathrm{t}}$ that enables access to larger pores behind the throat. The NMR relaxation time is related to the pore body radius $r_{\mathrm{b}}$. We assume that the IP signals are caused by the ion-selected active zones in the narrow pores that are comparable with the pore throats.

Regarding the differences in the methods, we present an approach that combines the curves to get more information on the pore space. Considering the two kinds of pore radii, $r_{\mathrm{b}}$ and $r_{\mathrm{t}}$, we first use $\mu$-CT and NMR to generate a combined curve displaying $V_{\mathrm{c}}$ as a function of $r_{\mathrm{b}}$. In the next step, we link the curves resulting from MIP and SIP to get a curve showing $V_{\mathrm{c}}$ as a function of the pore throat radius $r_{\mathrm{t}}$.

It is fundamental that the total pore volume (or total porosity) has to be known. The cumulative pore volume fraction should only consider the pore volume that is resolved in the regarded range of pore radii. Considering the resolution of $\mu$ $\mathrm{CT}$, only the pore space with radii larger than the voxel size is determined. The cumulative pore volume fraction at the limit of resolution has to be adjusted to the unresolved pore volume. In this way, the $\mu$-CT curve gets a fixed position in the $V_{\mathrm{c}}-r$ plot. Regarding NMR, the relaxation time $T_{2}$ has to be transformed into a pore radius according to Eq. (5). The application of Eq. (5) requires knowledge of the surface relaxivity $\rho$, which is the necessary scaling factor that causes a shift of the $V_{\mathrm{c}}-r$ curve along the axis of pore radius. Since the NMR method is sensitive to the pore body radius, we expect a similar $V_{\mathrm{c}}-r$ curve for NMR and $\mu$-CT in the overlapping range of pore body radii. The NMR curve is shifted along the axis of pore body radii until a good agreement between the two curves is reached. This procedure enables the determination of the surface relaxivity. The proposed alternative method for the determination of surface relaxivity considers the reduction of NMR relaxation time $T_{2}$ caused by high clay content and iron-bearing minerals (e.g., Keating and Knight, 2010).

MIP is used to generate the curve displaying $V_{\mathrm{c}}$ as a function of $r_{\mathrm{t}}$ over a wide range of pore throat radii. The SIP curve is fixed at the MIP curve considering the coincidence at the largest pore radius resolved by SIP.

The two curves representing $V_{\mathrm{c}}$ as a function of both $r_{\mathrm{b}}$ and $r_{\mathrm{t}}$ are displayed in a double-logarithmic plot. The horizontal shift of the two graphs represents the ratio $r_{\mathrm{b}} / r_{\mathrm{t}}$. Additionally, the slope of the curves is related to the fractal dimension.

The proposed approach in this study results in two pore size distribution curves for the two samples, which are in good accordance to the general pore space structures as described in Sect. 3 and as visualized in Fig. 2 (panels a to f). The first curve combines the distributions resulting from $\mu$ $\mathrm{CT}$ and NMR. The $\mu$-CT data provide a pore radius, which is regarded as pore body radius, without any scaling. The scaling of the NMR curve provides an estimate of the surface relaxivity. The surface relaxivity of the Bentheimer sample reaches $54 \mu \mathrm{m} \mathrm{s}^{-1}$, the corresponding value of the Röttbacher sample is much higher with $237 \mu \mathrm{m} \mathrm{s}^{-1}$. The higher 
surface relaxivity in comparison with the Bentheimer sample is clearly justified considering the larger specific surface area (Table 1) and the significantly higher content of clay and iron-bearing minerals as indicated in Table 2.

The two cumulative pore volume distribution curves for the Röttbacher sample (Fig. 8) indicate, over the wide range of pore radii, a parallel progression with consistently higher values for the pore body radius ( $\mu$-CT and NMR) in comparison with the pore throat radius (MIP). The horizontal distance of the two curves yields the ratio $r_{\mathrm{b}} / r_{\mathrm{t}}$. It should be noted that the ratio $r_{\mathrm{b}} / r_{\mathrm{t}}$ may vary with pore sizes. Most studies only consider a fixed ratio $r_{\mathrm{b}} / r_{\mathrm{t}}$ determined from the dominant pore body size from NMR $r_{\mathrm{b}}$ and the dominant pore throat size from MIP $r_{\mathrm{t}}$ (e.g., Müller-Huber et al., 2018). Regarding the median pore radii at $V_{\mathrm{c}}=0.5$, a ratio $r_{\mathrm{b}} / r_{\mathrm{t}}=9.13$ is determined. Considering smaller pores, a ratio $r_{\mathrm{b}} / r_{\mathrm{t}}=12.15$ is indicated at $V_{\mathrm{c}}=0.05$.

The parallelism of the pore volume distribution curve is less developed for the Bentheimer sample (Fig. 4). We observe a clear distance between the two curves in the range of larger pore radii. Regarding the median pore radii at $V_{\mathrm{c}}=0.5$, a ratio $r_{\mathrm{b}} / r_{\mathrm{t}}=2.57$ is determined. For $V_{\mathrm{c}}<0.2$, the slopes of the curves decrease and smaller distances between the curves are observed. The NMR curve in Fig. 5 indicates, for $V_{\mathrm{c}}>0.08$, larger pore radii in comparison with the MIP curve and confirms the relationship $r_{\mathrm{b}}>r_{\mathrm{t}}$. The reverse behavior in the interval $0.1 \mu \mathrm{m}<r<0.6 \mu \mathrm{m}$ is possibly caused by the low volume fraction $(3 \%)$ attributed to this range of pore radii. It can be expected that the small amount of water in the small pores causes only weak signals in the NMR relaxometry.

Besides the distances between the curves, the individual slopes are regarded. The slope $(s)$ of the curve $\log \left(V_{\mathrm{c}}\right)$ versus $\log (r)$ is related to the fractal dimension $D$ of the pore volume $(D=3-s)$ (Zhang and Weller, 2014). We observe a varying slope in the investigated range of pore radii for the Bentheimer sample. The only range of more or less constant slope, which extends from pore radius 0.1 to $10 \mu \mathrm{m}$, corresponds to a fractal dimension $D_{\mathrm{MIP}}=2.678$ for MIP, $D_{\mathrm{NMR}}=2.776$ for NMR, and $D_{\mathrm{SIP}}=2.618$ for SIP.

The whole curves of the four methods are nonlinear and indicate non-fractal behavior. A maximum likelihood estimator approach (MLE) might be relevant to extract the underlying scaling parameters (Rizzo et al., 2017). For example, in the case of the NMR curve of Bentheimer sandstone, the fitting of all data using the MLE reveals that the log-normal distribution is the most likely distribution with the estimated parameters $\mu=3.43$ and $\sigma=0.82 \mu \mathrm{m}$. These two scaling parameters are the logarithmic mean and logarithmic standard deviation of the pore radius, respectively. We recognize that the resulting mean radius reaches half the value of the effective hydraulic radius $\left(r_{\text {eff }}=6.97 \mu \mathrm{m}\right)$.

We observe a constant slope of the NMR curve for the Röttbacher sample (Fig. 8) in the interval $0.01 \mu \mathrm{m}<r_{\mathrm{b}}<$ $100 \mu \mathrm{m}$. A similar slope is observed for the MIP curve in the interval $0.01 \mu \mathrm{m}<r_{\mathrm{t}}<10 \mu \mathrm{m}$. Considering the overlapping pore throat radii range between 0.1 and $10 \mu \mathrm{m}$, a fractal dimension $D$ with values of 2.640 for MIP, and 2.661 for NMR has been determined. The slightly higher slope of the SIP curve results in a lower value of fractal dimension of $D=2.533$.

Our approach enables the integration of SIP in the determination of a pore throat size distribution. Considering the limited frequency range, only a limited range of pore throat radii can be reflected. Using a fixed diffusion coefficient $D_{(+)}=$ $3.8 \times 10^{-12} \mathrm{~m}^{2} \mathrm{~s}^{-1}$, a range of pore throat radii between 0.1 and $10 \mu \mathrm{m}$ is resolved. The SIP curve is linked to the MIP curve at $r=10 \mu \mathrm{m}$. An extension to lower pore radii would require the integration of higher frequencies. The removal of electromagnetic coupling effects can be one first step to improve the reliability of complex conductivity spectra for frequencies larger than $100 \mathrm{~Hz}$, but it should be regarded that smaller pore sizes are hidden by Maxwell-Wagner and dielectric relaxation. The proposed procedure results in a fair agreement between SIP and MIP curves in the overlapping range of pore throat radius for both the Bentheimer and the Röttbacher sample. In comparison with MIP, a slight overestimation of $V_{c}$ is observed for larger pore throat radii and a underestimation for lower pore throat radii. Considering the two samples of the presented study, the assumption of a constant diffusion coefficient seems to be justified. Although alternative kernels have not been tested, our study confirms that the Debye decomposition provides a relaxation time distribution of complex conductivity spectra that can be transformed in a pore throat size distribution comparable with the resulting curves from MIP. Regarding the discussion on the most relevant parameter that controls the relaxation time, our assumption that the pore throat radius is related to the relaxation time is supported by the results.

The investigations by $\mu$-CT, MIP, NMR, and SIP on the sandstone samples have been done in the laboratory. $\mu$-CT and MIP are methods that can only be applied on rock samples. The potential of these methods to derive pore size distributions is well acknowledged. NMR and SIP are methods that can also be performed in boreholes or as field survey. The NMR method has been successfully applied in permeability prediction at the field scale. A variety of permeability prediction models based on SIP parameters has been proposed based on laboratory investigations (e.g., Robinson et al., 2018). First tests have demonstrated their applicability in the field. Most permeability models consider pore size and porosity as the most important parameters. The evaluation of pore sizes of sediments at the field scale is a challenging task for geophysical methods. Our laboratory study has demonstrated the potential of SIP in identifying a pore size distribution. Further investigations with larger sets of samples have to be done to improve the proposed procedure before the pore size distribution can be extracted from high-quality complex conductivity field spectra. 


\section{Conclusions}

Pore radius distributions (considering both pore body and pore throat radii) have been determined by different methods ( $\mu$-CT, MIP, NMR, and SIP) for two sandstone samples. The curves presenting the cumulative distribution of pore volume $V_{\mathrm{c}}$ as a function of pore size have proved to be a suitable tool for comparison. It becomes obvious that the distribution curves indicate remarkable differences that are based on the physical principles of the used methods. The methods differ with regard to their limits of resolution. The effective resolution of $\mu$-CT is limited by the voxel size $(1.75 \mu \mathrm{m})$. Larger pores can be easily detected, whereas quantification of small pores and volumes of pores with small radii is severely affected by the image quality and the image processing algorithms. The MIP yields the widest range of pore radii. The pore throat radii are directly related to the pressure interval. A similar wide range of pore radii can be achieved by NMR. However, the transformation of the NMR transversal relaxation time into a pore body radius requires the surface relaxivity as scaling factor. In a similar way, the transformation of the electrical relaxation time resulting from SIP into a pore radius is based on a scaling factor that depends on the diffusion coefficient. Only a restricted range of pore radii ( 0.1 to $10 \mu \mathrm{m})$ can be resolved by SIP.

Besides the range of pore radii, the geometrical extent of the pore radius differs among the methods. $\mu$-CT enables a geometrical description of the individual pore space considering the shape of the pore. The pore radius can be determined in different ways. We use the average pore radius as an equivalent for the pore body radius $r_{\mathrm{b}}$. MIP is sensitive to the pore throat radius $r_{\mathrm{t}}$ that enables access to larger pores behind the throat. The NMR relaxation time is related to an average pore body radius $r_{\mathrm{b}}$. We assume that the IP signals are caused by the ion-selected active zones in the narrow pores that are comparable with the pore throats.

Considering the two kinds of pore radii $r_{\mathrm{b}}$ and $r_{\mathrm{t}}$, we use $\mu$ $\mathrm{CT}$ and NMR to generate a combined curve displaying $V_{\mathrm{c}}$ as a function of $r_{\mathrm{b}}$. A good agreement between the two curves is achieved if they coincide at $V_{\mathrm{c}}=0.5$. This condition is used to determine the surface relaxivity, which is in good accordance to the investigated surface area and mineralogy of the sample materials. MIP is used to generate the curve displaying $V_{\mathrm{c}}$ as a function of $r_{\mathrm{t}}$ over a wide range of pore throat radii. The SIP curve is fixed at the MIP curve considering the coincidence at the largest pore radius resulting from SIP.

The two curves representing $V_{\mathrm{c}}$ as a function of both $r_{\mathrm{b}}$ and $r_{\mathrm{t}}$ are displayed in a double-logarithmic plot. The horizontal shift of the two graphs represents the ratio $r_{\mathrm{b}} / r_{\mathrm{t}}$. Additionally, the slope of the curves is related to the fractal dimension.

The investigations on the samples demonstrate that the porosity increases using a method with a higher resolution. Both porosity and pore volume are parameters that depend on the resolution. The fractal dimension describes the size of geometric objects as a function of resolution. Therefore, the knowledge of fractal behavior enables upscaling and downscaling of geometric quantities. The Bentheimer sandstone sample is characterized by a ratio $r_{\mathrm{b}} / r_{\mathrm{t}}=2.57$ for the larger pores. A fractal behavior is observed in the range of pore radii between 0.1 and $10 \mu \mathrm{m}$ with an average $D=2.69$ determined for the pore volume by MIP, NMR, and SIP. The Röttbacher sandstone sample indicates a larger ratio between pore body radius and pore throat with $r_{\mathrm{b}} / r_{\mathrm{t}}=9.13$ in comparison to the Bentheimer sample. An average fractal dimension of $D=2.61$ is determined for the Röttbacher sample.

Data availability. The SIP-Archiv repository has been developed by Halisch et al. (2016c, 2017) in collaboration with the Working Group "Induced Polarization" (AK IP) of the German Geophysical Society (DGG).

Author contributions. The four authors have designed the project in close cooperation. SK has selected and provided the samples for the study. The measurements have been done in the labs of the institutions of MH, SK, and AW. MH provided the DIA of the $\mu$-CT data. $\mathrm{ZZ}$ and $\mathrm{AW}$ developed the algorithm to integrate the pore size distribution from SIP data. The four authors contributed to the discussion of the results and to writing and improving the manuscript. ZZ designed all figures.

Competing interests. The authors declare that they have no conflict of interest.

Acknowledgements. The authors thank Sven Nordsiek (University Bayreuth) for the Debye decomposition of the SIP data, Dietmar Meinel (BAM, Berlin) for supporting the CT analysis, Carsten Prinz (BAM, Berlin) for providing the MIP data, and Mike Müller-Petke as well as Raphael Dlugosch (both Leibniz Institute for Applied Geophysics, Hanover) for the acquisition of the NMR spectra for this study. Zeyu Zhang thanks Bundesanstalt für Materialforschung und -prüfung (BAM, Berlin) for the Adolf-Martens-Fellowship that enabled his stay in Germany for the experimental research.

Edited by: Michael Heap

Reviewed by: Alodie Bubeck, David Healy, and two anonymous referees

\section{References}

API (American Petroleum Institute): Recommended Practices for Core Analysis, API Recommended Practice 40, chap. 6 - permeability determination, 2nd Edn., API Publishing Services, 1220 L Street, N.W., Washington, DC, 1998.

Avnir, D. and Jaroniec, M.: An isotherm equation for adsorption on fractal surfaces of heterogeneous porous materials, Langmuir, 5, 1412-1433, 1989. 
Avnir, D., Farin, D., and Pfeifer, P.: Molecular fractal surfaces, Nature, 308, 261-263, 1984.

Behroozmand, A., Keating, K., and Auken, E.: A review of the principles and applications of the NMR technique for near-surface characterization, Surv. Geophys., 36, 27-85, https://doi.org/10.1007/s10712-014-9304-0, 2015.

Binley, A., Slater, L. D., Fukees, M., and Cassiani, G.: Relationship between spectral induced polarization and hydraulic poroperties of saturated and unsaturated sandstone, Water Resour. Res., 41, W12417, https://doi.org/10.1029/2005WR004202, 2005.

Ding, Y., Weller, A., Zhang, Z., and Kassab, M.: Fractal dimension of pore space in carbonate samples from Tushka Area (Egypt), Arab. J. Geosci., 10, 388, https://doi.org/10.1007/s12517-0173173-z, 2017.

Dubelaar, W. C. and Nijland, T. G.: The Bentheim Sandstone: geology, petrophysics, varieties and its use as dimension stone, in: Engineering Geology for Society and Territory, edited by: Lollino, G., Giordan, D., Marunteanu, C., Christaras, B., Yoshinori, I., and Margottini, C., Springer International Publishing, Switzerland, Vol. 8, 557-563, 2015.

Florsch, N., Revil, A., and Camerlynck, C.: Inversion of generalized relaxation time distributions with optimized samping parameter, J. Appl. Geophys., 109, 119-132, 2014.

Gaboreau, S., Robinet, J. C., Tournassat, C., and Savoye, S.: Diffuse transport in clay media: $\mu \mathrm{m}$ to $\mathrm{nm}$ scale characterization of pore space and mineral spatial organization: International Meeting Clays in Natural and Engineered Barriers for Radioactive Waste Confinement, Montpellier, France, 2012.

Halisch, M., Schmitt, M., and Fernandes, C. P.: Pore Shapes and Pore Geometry of Reservoirs Rocks from $\mu$-CT Imaging and Digital Image Analysis, in: Proceedings of the Annual Symposium of the SCA 2016, Snowmass, Colorado, USA, 21-26 August 2016, SCA2016-093, 2016a.

Halisch, M., Steeb, H., Henkel, S., and Krawczyk, C. M.: Pore-scale tomography and imaging: applications, techniques and recommended practice, Solid Earth, 7, 1141-1143, https://doi.org/10.5194/se-7-1141-2016, 2016b.

Halisch, M., Gramenz, J., Gorling, L., Krause, K., and Bolotovski, I.: An internet based, interactive archive and database for SIP data, 4th International Workshop on Induced Polarization, Aarhus, Denmark, http://www.sip-archiv.de (last access: 1 November 2018), 2016c.

Halisch, M., Kruschwitz, S., Martin, T., and SIP-Archiv EntwicklerTeam: Ein internetbasiertes Archiv- und Austauschsystem für Messdaten der Spektralen Induzierten Polarisation. Mitteilungen der Deutschen Geophysikalischen Gesellschaft e.V., 1/2017, ISSN 0934-6554, p. 31 ff., 2017.

Keating, K. and Knight, R.: A laboratory study of the effect of $\mathrm{Fe}$ (II)-bearing minerals on nuclear magnetic resonance (NMR) relaxation measurements, Geophysics, 75, F71-F82, 2010.

Keller, L. M., Holzer, L., Wepf, R., Gasser, P., Münch, B., and Marschall, P.: On the application of focused ion beam nanotomography in characterizing the $3 \mathrm{D}$ pore space geometry of Opalinus clay, Phys. Chem. Earth, 36, 1539-1544, https://doi.org/10.1016/j.pce.2011.07.010, 2011.

Kelokaski, M., Siitari-Kauppi, M., Sardini, P., Mori, A., and Hellmuth, K. H.: Characterisation of pore space geometry by ${ }^{14} \mathrm{C}$-PMMA impregnation-development work for in situ studies, J. Geochem. Explor., 90, 45-52, https://doi.org/10.1016/j.gexplo.2005.09.005, 2005.

Kleinberg, R. L.: Utility of NMR $T_{2}$ distributions, connection with capillary pressure, clay effect, and determination of the surface relaxivity parameter $\rho 2$, Magn. Reson. Imaging, 14, 761-767, 1996.

Klinkenberg, L. J.: The permeability of porous media to liquids and gases, API Drill and Production Practices, 200-213, 1941.

Kruschwitz, S., Prinz, C., and Zimathies, A.: Study into the correlation of dominant pore throat size and SIP relaxation frequency, J. Appl. Geophys., 135, 375-386, 2016.

Leroy, P., Revil, A., Kemna, A., Cosenza, P., and Gorbani, A.: Spectral induced polarization of water-saturated packs of glass beads, J. Colloid Interf. Sci, 321, 103-117, https://doi.org/10.1016/j.jcis.2007.12.031, 2008.

Mandelbrot, B. B.: Fractals: form, chance, and dimension, Freeman, San Francisco, 1977.

Mandelbrot, B. B.: Fractal geometry of nature, Freeman, San Francisco, 1983.

Mancuso, C., Jommi, C., and D’Onza, F. (Eds.): Unsaturated Soils: Research and Applications, Vol. 1, Springer-Verlag, Berlin Heidelberg, 123-130, https://doi.org/10.1007/978-3-642-31116$1,2012$.

Mees, F., Swennen, R., van Geet, M., and Jacobs, P. (Eds.): Applications of X-ray computed tomography in the geosciences, Geol. Soc. Spec. Publ., 215, 1-6, https://doi.org/10.1144/GSL.SP.2003.215.01.01, 2003.

Meyer, K., Klobes, P., and Röhl-Kuhn, B.: Certification of reference material with special emphasis on porous solids, Cryst. Res. Technol., 32, 173-183, 1997.

Müller-Huber, E., Börner, F., Börner, J. H., and Kulke, D.: Combined interpretation of NMR, MICP, and SIP measurements on mud-dominated and grain-dominated carbonate rocks, J. Appl. Geophys., 159, 228-240, https://doi.org/10.1016/j.jappgeo.2018.08.011, 2018.

Niu, Q. and Revil, A.: Connecting complex conductivity spectra to mercury porosimetry of sedimentary rocks, Geophysics, 81, E17-E32, https://doi.org/10.1190/GEO2015-0072.1, 2016.

Niu, Q. and Zhang, C.: Joint inversion of NMR and SIP data to estimate pore size distribution of geomaterials, Geophys. J. Int., 212, 1791-1805, https://doi.org/10.1093/gji/ggx501, 2017.

Nordsiek, S. and Weller, A.: A new approach to fitting induced-polarization spectra, Geophysics, 73, F235-F245, https://doi.org/10.1190/1.2987412, 2008.

Pape, H., Riepe, L., and Schopper, J. R.: A pigeon-hole model for relating permeability to specific surface, Log Analyst., 23, 5-13, 1982.

Pape, H., Arnold, J., Pechnig, R., Clauser, C., Talnishnikh, E., Anferova, S., and Blümlich, B.: Permeability prediction for low porosity rocks by mobile NMR, Pure Appl. Geophys., 166, 1125-1163, 2009.

Peksa, A., Wolf, K., and Zitha, P.: Bentheimer sandstone revisited for experimental purposes, Mar. Petrol. Geol., 67, 701-719, https://doi.org/10.1016/j.marpetgeo.2015.06.001, 2015.

Peth, S., Horn, R., Beckmann, F., Donath, T., Fischer, J., and Smucker, A. J. M.: Three-dimensional quantification of intraaggregate pore-space features using Synchrotron-RadiationBased Microtomography, Soil Sci. Soc. Am. J., 72, 897-907, https://doi.org/10.2136/sssaj2007.0130, 2008. 
Revil, A.: Effective conductivity and permittivity of unsaturated porous materials in the frequency range $1 \mathrm{mHz}-1 \mathrm{GHz}$, Water Resour. Res., 49, 306-327, https://doi.org/10.1029/2012WR012700, 2013.

Revil, A. and Florsch, N.: Determination of permeability from spectral-induced-polarization data in granular media, Geophys. J. Int., 181, 1480-1498, 2010.

Revil, A., Koch, K., and Holliger, K.: Is it the grain size or the characteristic pore size that controls the induced polarization relaxation time of clean sands and sandstones?, Water Resour. Res., 48, W05602, https://doi.org/10.1029/2011WR011561, 2012.

Revil, A., Florsch, N., and Camerlynck, C.: Spectral induced polarization porosimetry, Geophys. J. Int., 198, 1016-1033, https://doi.org/10.1093/gji/ggu180, 2014.

Rieckmann, M.: Untersuchung von Turbulenzerscheinungen beim Fließen von Gasen durch Speichergesteine unter Berücksichtigung der Gleitströmung, Erdöl-Erdgas-Zeitschrift, 6, 36-51, 1970.

Rizzo, R. E., Healy, D., and De Siena, L.: Benefits of maximum likelihood estimators for fracture attribute analysis: Implications for permeability and up-scaling, J. Struct. Geol., 95, 17-31, https://doi.org/10.1016/j.jsg.2016.12.005, 2017.

Robinson, J., Slater, L., Weller, A., Keating, K., Robinson, T., Rose, C., and Parker, B.: On permeability prediction from complex conductivity measurements using polarization magnitude and relaxation time, Water Resour. Res., 54, 3436-3452, https://doi.org/10.1002/2017WR022034, 2018.

Rouquerol, J., Avnir, D., Fairbridge, D. C. W., Everett, D. H., Haynes, J. H., Pernicone, N., Ramsay, J. D. F., Sing, K. S. W., and Unger, K. K.: Recommendations for the characterization of porous solids (Technical Report), Pure Appl. Chem., 66, 17391758, 1994.

Schleifer, N., Weller, A., Schneider, S., and Junge, A.: Investigation of a Bronze Age plankway by spectral-inducedpolarization, Archeological Prospection, 9, 243-253, https://doi.org/10.1002/arp.194, 2002.

Schmitt, M., Halisch, M., Müller, C., and Fernandes, C. P.: Classification and quantification of pore shapes in sandstone reservoir rocks with 3-D X-ray micro-computed tomography, Solid Earth, 7, 285-300, https://doi.org/10.5194/se-7-285-2016, 2016.

Schwarz, G.: A theory of the low-frequency dielectric dispersion of colloidal particles in electrolyte solution, J. Phys. Chem., 66, 2636-2642, https://doi.org/10.1021/j100818a067, 1962.
Scott, J. B. T. and Barker, R. D.: Determining pore-throat size in Permo-Triassic sandstones from low-frequency electrical spectroscopy, Geophys. Res. Lett., 30, 1450, https://doi.org/10.1029/2003GL016951, 2003.

Silin, D. and Patzek, T.: Pore space morphology analysis using maximal inscribed spheres, Phys. A, 371, 336-360, https://doi.org/10.1016/j.physa.2006.04.048, 2006.

Slater, L. and Lesmes, D. P.: Electric-hydraulic relationships observed for unconsolidated sediments, Water Resour. Res., 38, 31 1-31-13, https://doi.org/10.1029/2001WR001075, 2002.

Terasov, A. and Titov, K.: Relaxation time distribution from time domain induced polarization measurements, Geophys. J. Int., 170, 31-43, https://doi.org/10.1111/j.1365-246X.2007.03376.x, 2007.

Thomeer, J. H. M.: Introduction of a pore geometrical factor defined by the capillary pressure curve, J. Petrol. Technol., 12, 73-77, 1960.

Washburn, E. W.: The dynamics of capillary flow, Phys. Rev., 17, 273-283, 1921.

Weigand, M. and Kemna, A.: Debye decomposition of time-lapse spectral-induced-polarization data, Comput. Geosci., 86, 34-45, https://doi.org/10.1016/j.cageo.2015.09.021, 2016.

Weller, A., Nordsiek, S., and Debschütz, W.: Estimating permeability of sandstone samples by nuclear magnetic resonance and spectral-induced polarization, Geophysics, 75, E215-E226, https://doi.org/10.1190/1.3507304, 2010.

Weller, A., Slater, L., Binley, A., Nordsiek, S., and Xu, S.: Permeability prediction based on induced polarization: Insights from measurements on sandstone and unconsolidated samples spanning a wide permeability range, Geophysics, 80, D161-D173, https://doi.org/10.1190/GEO2014-0368.1, 2015.

Weller, A., Zhang, Z., Slater, L., Kruschwitz, S., and Halisch, M.: Induced polarization and pore radius - a discussion, Geophysics, 81, 519-526, https://doi.org/10.1190/GEO2016-0135.1, 2016.

Zhang, Z. and Weller, A.: Fractal dimension of pore space geometry of an Eocene sandstone formation, Geophysics, 79, D377-D387, https://doi.org/10.1190/GEO2014-0143.1, 2014.

Zhang, Z., Weller, A., and Kruschwitz, S.: Pore radius distribution and fractal dimension derived from spectral-inducedpolarization, Near Surf. Geophys., 15, 625-632, 2017.

Zimmermann, E., Kemna, A., Berwix, J., Glaas, W., and Vereecken, H.: EIT measurement system with high phase accuracy for the imaging of spectral induced polarization properties of soils and sediments, Meas. Sci. Technol., 19, 094010, https://doi.org/10.1088/0957-0233/19/9/094010, 2008. 